\title{
Desenvolvimento de Alimento Probiótico de Leite de Coco Sem Açúcar Adicionado
}

\author{
Sabrina Pereira Messa ${ }^{1}$, Cássia Regina Nespolo ${ }^{2}$, Carla Pohl Sehn ${ }^{3}$, \\ Franciane Cabral Pinheiro ${ }^{4}$, Morgana Balbueno Ferreira ${ }^{5}$, Giovana Magalhães Soares ${ }^{6}$
}

\begin{abstract}
RESUMO
A alimentação saudável é foco de muitos consumidores, principalmente os com restrições alimentares, com o uso crescente de probióticos e interesse por alimentos isentos de lactose. Como os probióticos são normalmente ingeridos em alimentos lácteos, o objetivo deste estudo foi desenvolver um alimento preparado com leite de coco, adição de probióticos e sem açúcar agregado. As amostras foram armazenadas sob refrigeração $\left(7^{\circ} \mathrm{C}\right)$ e foram avaliados $\mathrm{pH}$, atividade de água, acidez titulável, bactérias lácticas, coliformes totais e termotolerantes, psicrotróficos e bolores e leveduras. Os resultados de $\mathrm{pH}$ e atividade de água demostraram condições para proliferação de microrganismos indesejáveis e dificuldades para manutenção das bactérias probióticas. A acidez variou entre 0,11 e 0,14 \% de ácido láctico e as contagens para coliformes totais e termotolerantes foram adequadas. As contagens médias de bactérias lácticas variaram de 3,40 a 4,09 log UFC/g e de bolores e leveduras foram de 3,38 a 9,48 log UFC/g, respectivamente, abaixo e acima dos padrões legais para produtos lácteos similares. Para o alimento à base de leite de coco ser uma alternativa de alimento vegetal contendo probióticos em quantidade adequada, seria necessário adicionar uma dose inicial maior de probióticos e facilitadores de multiplicação destas bactérias, como monossacarídeos ou dissacarídeos. Novos estudos estão em andamento buscando aprimorar a formulação deste alimento de coco contendo probióticos.
\end{abstract}

Palavras-chave: Alimento funcional. Produtos vegetais. Tecnologia de alimentos. Análise microbiológica. Análise físico-química.

\section{DEVELOPMENT OF COCONUT MILK PROBIOTIC FOOD WITHOUT ADDED SUGAR}

\begin{abstract}
Healthy eating is aim of many consumers, especially those with dietary restrictions, increasing the use of probiotics and interest in lactose-free foods. As probiotics are usually ingested in dairy foods, the objective of this study was to develop an alternative product prepared with coconut milk, probiotics addition and no added sugar. Samples were stored under refrigeration $\left(7^{\circ} \mathrm{C}\right)$ and the $\mathrm{pH}$, water activity, titratable acidity, lactic acid bacteria, total coliforms and thermotolerant, psychrotrophic and mold and yeast were evaluated. Results for $\mathrm{pH}$ and water activity demonstrated conditions for proliferation of undesirable microorganisms and difficulties for maintenance of probiotic bacteria. The acidity varied between 0.11 and $0.14 \%$ of lactic acid and counts for total and thermotolerant coliforms were adequate. Mean counts of lactic acid bacteria ranged from 3.40 to $4.09 \mathrm{log}$ CFU/g, and yeasts and molds were 3.38 to $9.48 \mathrm{log}$ CFU/g, respectively, below and above legal standards for similar dairy products. For coconut milk food be an alternative to vegetable food containing probiotics in adequate quantity, it would be necessary to add a larger initial dose of probiotics and facilitators of multiplication of these bacteria, such as monosaccharides or disaccharides. Further studies are underway to improve the formulation of this coconut milk probiotic food.
\end{abstract}

Keywords: Functional food. Vegetable products. Food technology. Microbiological analysis. Physicochemical analysis.

RECEBIDO EM: 13/3/2019

MODIFICAÇÕES REQUERIDAS EM: 27/9/2019

ACEITO EM: 2/10/2019

\footnotetext{
Bacharel em Nutrição - Universidade Federal do Pampa (Unipampa), Campus Itaqui, RS, Brasil. sabrinamessa10@gmail.com

2 Farmacêutica Bioquímica e Tecnologia de Alimentos (UFRGS). Mestre e doutora em Microbiologia Agrícola e do Ambiente (UFRGS). Professora-adjunta de Ciência e Tecnologia de Alimentos - Universidade Federal do Pampa (Unipampa), Campus São Gabriel/RS. ccassianespolo@unipampa.edu.br

${ }^{3}$ Nutricionista. Doutora em Ciência e Tecnologia de Alimentos (UFPel). Professora Adjunta de Nutrição - Universidade Federal do Pampa (Unipampa), Campus Itaqui, RS, Brasil. carlasehn@unipampa.edu.br

${ }^{4}$ Bióloga. Doutoranda em Bioquímica - Universidade Federal do Pampa (Unipampa), Campus Itaqui, RS, Brasil. fcabralpinheiro@gmail.com

${ }^{5}$ Bacharel em Nutrição - Universidade Federal do Pampa (Unipampa), Campus Itaqui, RS, Brasil. morgana-bf@hotmail.com

${ }^{6}$ Estudante do Bacharelado Interdisciplinar em Ciência e Tecnologia - Universidade Federal do Pampa (Unipampa), Campus Itaqui, RS, Brasil. soaresgiovana24@yahoo.com.br
} 


\section{INTRODUÇÃO}

A preocupação com a alimentação tornou-se comum na sociedade atual, com demanda crescente por alimentos que contribuam para a saúde, qualidade de vida e manutenção de uma condição fisiológica salubre (MIJAN; LIM, 2018). A busca por uma dieta rica em nutrientes é considerada aliada na prevenção de doenças crônicas não transmissíveis (FOROUHI et al., 2018; MIJAN; LIM, 2018), e os alimentos funcionais estão inseridos neste contexto, com o objetivo de promover uma alimentação equilibrada e proporcionar benefícios à saúde do consumidor, desde que associados a hábitos de vida saudáveis (ANVISA, 2016; MIJAN; LIM, 2018).

O coco (Cocos nucifera L.) é um alimento associado à prevenção de doenças, com estudos indicando potencial atividade anti-inflamatória, antioxidante e antimicrobiana, dentre outras (PATIL; BENJAKUL, 2018). A polpa do coco contém $43 \%$ a $61 \%$ de umidade, $21 \%$ a $42 \%$ de lipídios, de $5,4 \%$ a $8,1 \%$ de carboidratos disponíveis, 5,0\% de fibra alimentar, 3,7\% a $4,0 \%$ de proteínas e $0,9 \%$ a $1,1 \%$ de minerais, especialmente potássio, fósforo e magnésio, com valor energético de $406 \mathrm{kcal} / 100 \mathrm{~g}$ (FOOD..., 2017; NEPA, 2019; PATIL et al., 2017). O leite de coco é uma emulsão obtida por meio da extração do endosperma sólido do coco, com ou sem adição de água (PATIL; BENJAKUL, 2018), com $78 \%$ de umidade, $18 \%$ de lipídios, $1,5 \%$ de carboidratos disponíveis, $0,7 \%$ de fibra alimentar, $0,6 \%$ de proteína, $2,6 \%$ de minerais e valor energético de $302 \mathrm{kcal} / 100 \mathrm{~g}$ (NEPA, 2019) suplementação dietética com probióticos também é uma estratégia utilizada com vistas ao benefício à saúde humana, uma vez que consistem em microrganismos vivos que, quando administrados em quantidades adequadas, proporcionam benefícios ao indivíduo que o recebe (MCFARLAND, 2015; MIJAN; LIM, 2018). Alguns microrganismos comumente usados como probióticos são: Bifidobacterium bifidum, Lactobacillus acidophilus, Lactobacillus bulgaricus, Lactobacillus casei, Lactobacillus plantarum, Lactobacillus reuteri, Lactobacillus rhamnosus e Saccharomyces boulardii (MCFARLAND, 2015). Dentre os estudos envolvendo probióticos, os efeitos benéficos à saúde mais comuns foram regulação do trânsito intestinal, normalização da microbiota intestinal e exclusão competitiva de patógenos (HILL et al., 2014; MCFARLAND, 2015; OZCAN et al., 2016). Há probióticos incluídos em alimentos ou suplementos que possuem uma alegação de saúde baseada em estudos científicos (ANVISA, 2016; HILL et al., 2014; MCFARLAND, 2015) e outros sem alegação de saúde, ou ainda a utilização de culturas vivas e ativas presen- tes em um alimento, normalmente envolvidas em algum processo de fermentação, como em iogurtes ou leites fermentados (HILL et al., 2014; MCFARLAND, 2015). O processamento de leites fermentados no Brasil tem como obrigatoriedade a utilização de culturas microbianas específicas, como Streptococcus salivarius subsp. thermophilus e Lactobacillus delbrueckii subsp. bulgaricus, dentre outras (BRASIL, 2007; HILL et al., 2014), e cumprir os requisitos de qualidade definidos pela Instrução Normativa n. 46, de 23 de outubro de 2007 (ALMEIDA et al., 2015; BRASIL, 2007), podendo haver introdução de microrganismos probióticos em alguns destes alimentos (FOROUHI et al., 2018) intolerância à lactose é uma patologia caracterizada pela diminuição ou ausência da enzima lactase no intestino delgado, ocasionando uma série de desordens gastrointestinais e levando à exclusão de alimentos lácteos da dieta (HEINE et al., 2017). Os produtos lácteos fermentados possuem uma quantidade menor de lactose, posto que as bactérias lácticas podem reduzir o conteúdo de lactose por meio do metabolismo da galactosidase bacteriana (HEINE et al., 2017; SZILAGYI; ISHAYEK, 2018). O consumo de produtos lácteos fermentados por intolerantes à lactose não pode ser considerado completamente seguro (SZILAGYI; ISHAYEK, 2018), por isso a formulação de alimentos fermentados ou fontes de probióticos isentos de lactose ou de proteína láctea tem como foco o equilíbrio da dieta de indivíduos intolerantes à lactose, alérgicos à proteína láctea ou com restrição ao consumo de produtos de origem animal. $O$ objetivo do presente trabalho foi desenvolver um alimento à base de leite de coco com adição de bactérias lácticas probióticas e sem adição de açúcar, avaliando parâmetros microbiológicos e físico-químicos durante o armazenamento refrigerado.

\section{MÉTODO}

A elaboração do alimento à base de coco foi realizada seguindo as boas práticas de manipulação de alimentos. O leite de coco foi obtido no comércio local e o ágar utilizado foi o bacteriológico (Himedia ${ }^{\circledR}$ ). As bactérias probióticas Lactobacillus delbrueckii subsp. bulgaricus, Streptococcus salivarius subsp. thermophilus, Lactobacillus acidophilus e Bifidobacterium animalis subsp. Lactis, foram compradas em empresas especializadas na forma liofilizada (BioRich ${ }^{\circledR}$, Docina $^{\circledR}$ ). O leite de coco foi aquecido em recipiente de aço inox, em fogo brando, até atingir a temperatura de $60^{\circ} \mathrm{C}$ e então foi adicionado o ágar na proporção de $18 \mathrm{~g}$ por litro, mexendo-se até completa dissolução. $\mathrm{O}$ recipiente foi retirado do fogo e a temperatura foi mo- 
nitorada com termômetro tipo espeto, até atingir $40^{\circ} \mathrm{C}$ a $45^{\circ} \mathrm{C}$. Em seguida, as bactérias foram adicionadas de acordo com as orientações e nas proporções indicadas pelos fabricantes, posto que uma marca indicava $0,4 \mathrm{~g}$ de bactérias liofilizadas para cada litro do alimento e, a outra, $1 \mathrm{~g}$ de bactérias liofilizadas para cada litro de alimento. Após, o alimento à base de leite de coco foi envasado em recipientes de vidro de $250 \mathrm{~g}$, com tampa rosca metálica, previamente limpos e esterilizados em autoclave, e armazenado em ambiente refrigerado (temperatura média de $7^{\circ} \mathrm{C}$ ) por 65 dias.

Foram analisados parâmetros de qualidade microbiológica e físico-química ao longo do armazenamento do alimento à base de leite de coco em duplicata. As coletas ocorreram a cada 15 dias, iniciando no quinto dia após a elaboração do produto, com três frascos avaliados em cada coleta. $\mathrm{O} \mathrm{pH}$ foi determinado utilizando-se medidor de $\mathrm{pH}$ modelo pg1800 (GEHAKA ${ }^{\circledR}$ ), previamente calibrado, nas amostras diluídas na proporção 1:10 (m/v) em água recentemente destilada, submetidas à homogeneização e posterior medição eletrométrica (IAL, 2008). A determinação da atividade de água ( $A w$ ) foi realizada diretamente na amostra sem diluição, utilizando-se o equipamento Aqualab 4TE (Decagon ${ }^{\circledR}$ ) seguindo as instruções do fabricante (DECAGON DEVICES, 2019). A acidez titulável foi determinada a partir da diluição da amostra em água destilada previamente fervida e neutralizada, seguida da titulação com solução de hidróxido de sódio $0,1 \mathrm{~N}$, na presença de solução indicadora de fenolftaleína $1 \%$, e os valores gastos foram calculados em acidez titulável em percentual $(\mathrm{m} / \mathrm{v})$ (IAL, 2008).

A avaliação microbiológica do alimento à base de leite de coco incluiu microrganismos indicadores de qualidade e baseou-se nos requisitos da legislação (BRASIL, 2001, 2007), quantificando-se bactérias lácticas, grupos coliformes totais, coliformes termotolerantes, psicrotróficos e bolores e leveduras. As amostras foram submetidas a uma diluição inicial de $25 \mathrm{~g}$ da amostra em $225 \mathrm{~mL}$ de água peptonada $0,1 \%$, com homogeneização em equipamento tipo Stomacher e diluições seriadas até $10^{-6}$. A determinação de bactérias lácticas foi realizada em placas contendo Ágar Man Rogosa e Sharpe (MRS, Merck ${ }^{\circledR}$ ) com incubação a $37 \pm 1$ 으, por 48-72 horas, em jarra de anaerobiose (DOWARAH et al., 2018). Na análise de coliformes, foi utilizada a técnica dos tubos múltiplos com tubo de Durhan invertido com as diluições $10^{-1}, 10^{-2}$ e $10^{-3}$ inoculadas em séries de três tubos contendo caldo lauril sulfato de sódio (Dinamica ${ }^{\circledR}$ ) em concentração dupla para teste presuntivo, a $36 \pm 1^{\circ} \mathrm{C}$, por $24-48$ ho- ras. A confirmação para coliformes totais foi realizada utilizando caldo verde brilhante lactose bile $2 \%(\mathrm{Hi}-$ media ${ }^{\circledR}$ ) com posterior incubação a $35 \pm 1^{\circ} \mathrm{C}$, durante 24-48 horas. Já a verificação da presença de coliformes termotolerantes foi realizada por meio do caldo Escherichia coli (EC, Himedia ${ }^{\circledR}$ ) com incubação a $45 \pm$ $0,2^{\circ} \mathrm{C}$ por $24-48$ horas. Após o período de incubação, foi realizada a leitura dos resultados e a quantificação do número mais provável (NMP), utilizando Tabela de Hoskins (SILVA et al., 2017). Para a contagem de psicrotróficos, empregou-se o método de plaqueamento em superfície em Ágar Padrão de Contagem (PCA), Himedia ${ }^{\circledR}$ ), com incubação a $7^{\circ} \mathrm{C}$, por dez dias (SILVA et al., 2017). A quantificação de bolores e leveduras foi determinada em placas de Ágar Batata Dextrose (BDA, Himedia ${ }^{\circledR}$ ) acidificado (pH 3,5) e incubação a $25 \pm 1^{\circ} \mathrm{C}$, por 5-7 dias (SILVA et al., 2017).

Os resultados foram organizados em programa Microsoft Excel 2010 para obter as médias e desvios padrão da média, e os valores das contagens microbiológicas foram convertidos em logaritmos (log). Os dados foram avaliados pelo programa ASSISTAT 7.7 beta, quando foi aplicada análise de variância seguida pelo Teste de Tukey ao nível de 5\% de significância.

\section{RESULTADOS E DISCUSSÃO}

A Tabela 1 apresenta os valores de $\mathrm{pH}, \mathrm{Aw}$ e acidez do alimento à base de leite de coco com adição de microrganismos probióticos durante o armazenamento refrigerado.

Tabela 1 - Valores de $\mathrm{pH}$, atividade de água (Aw) e acidez no alimento à base de leite de coco durante $\mathrm{o}$ armazenamento refrigerado

\begin{tabular}{l|c|c|c}
\hline Período & pH & Aw & $\begin{array}{c}\text { Acidez titulável } \\
\text { (\% de ácido } \\
\text { láctico) }\end{array}$ \\
\hline Dia 5 & $5,86 \pm 0,24^{\mathrm{c}}$ & $0,998 \pm 0,002^{\mathrm{ab}}$ & $0,12 \pm 0,02^{\mathrm{ab}}$ \\
\hline Dia 20 & $6,63 \pm 0,12^{\mathrm{a}}$ & $0,995 \pm 0,001^{\mathrm{b}}$ & $0,12 \pm 0,01^{\mathrm{ab}}$ \\
\hline Dia 35 & $6,31 \pm 0,02^{\mathrm{ab}}$ & $0,998 \pm 0,001^{\mathrm{ab}}$ & $0,14 \pm 0,01^{\mathrm{a}}$ \\
\hline Dia 50 & $6,03 \pm 0,05^{\mathrm{bc}}$ & $0,999 \pm 0,001^{\mathrm{a}}$ & $0,12 \pm 0,02^{\mathrm{ab}}$ \\
\hline Dia 65 & $6,10 \pm 0,10^{\mathrm{bc}}$ & $0,998 \pm 0,001^{\mathrm{ab}}$ & $0,11 \pm 0,01^{\mathrm{b}}$ \\
\hline Padrão* & - & - & $0,6 \mathrm{a} 2,0$ \\
\hline
\end{tabular}

Valores apresentados como média \pm desvio padrão da média ( $n=3)$; a-c: Letras iguais na mesma coluna não diferem estatisticamente entre si $(p<0,05)$ pelo Teste de Tukey; *Padrão para leites fermentados (BRASIL, 2007).

Os valores $\mathrm{pH}$ variaram significativamente de 5,86 , no 5o dia de armazenamento, a 6,63 no 20 응 dia, porém não foi observada variação significativa $(p, 0,05)$ entre a primeira e a última coleta. Estes re- 
sultados demonstram que os valores de $\mathrm{pH}$ não sofreram grandes alterações ao longo do armazenamento refrigerado, sendo valores próximos ao observado em estudo com a matéria-prima leite de coco, que apresentou pH 6,0 (LADOKUN; ONI, 2014). Em estudos com iogurtes desenvolvidos com adição de probióticos variados, como Lactobacillus acidophilus, Lactobacillus lactis, Lactobacillus casei, Bifidobacterium animalis subsp. lactis, Lactobacillus delbrueckii subsp. bulgaricus e Streptococcus thermophilus, o pH inicial foi de 6,5 , diminuindo para 4,10 a 4,60 durante a fermentação e mantendo-se assim ao longo do armazenamento (SARVARI; MORTAZAVIAN; FAZELI, 2014; YILMAZ-ERSAN; KURDAL, 2014). Da mesma forma, houve uma redução significativa do $\mathrm{pH}$ com extrato de arroz fermentado com probiótico Lactobacillus plantarum de 6,0 para em torno de 4,0 ao longo de 24 dias (SAVEDBOWORN et al., 2017). Estudos com bebidas fermentadas contendo leite de coco verificaram que o processo de fermentação por bactérias foi favorecido pela adição de leite em pó e açúcar, com valores de $\mathrm{pH}$ de 3,79 a 3,84 após 24 horas a 37 o $\mathrm{C}-42$ 으 após 72 horas de fermentação a 45C (LADOKUN; ONI, 2014). $\mathrm{O}$ teor de carboidratos disponíveis no leite de coco é baixo, cerca de 1,5\% (NEPA, 2019), portanto a adição de substratos fermentescíveis, como açúcar ou leite em pó (LADOKUN; ONI, 2014; YULIANA; RANGGA; RAKHMIATI, 2010), ou de prebióticos, como a inulina (WHITE; HEKMAT, 2018; SAVEDBOWORN et al., 2017), podem ser formas para atingir um $\mathrm{pH}$ mais baixo nestes alimentos.

A atividade de água (Aw) do alimento à base de leite de coco não apresentou variação entre as coletas inicial e final, variando significativamente $(p<0,05)$ apenas entre os tempos $20(0,995$ de $A w)$ e 50 dias $(0,999$ de Aw) (Tabela 1). Da mesma forma que o $\mathrm{pH}$, os valores de atividade de água encontrados no produto desenvolvido no presente estudo estão acima dos limites mínimos para multiplicação das bactérias patogênicas (FORSYTHE, 2013), o que torna imprescindível o monitoramento microbiológico neste alimento.

A acidez do alimento à base de leite de coco oscilou entre $0,11 \%$ e $0,14 \%$ de ácido láctico (Tabela 1), valores inferiores aos definidos pela legislação para os produtos fermentados de base láctea. Em estudo com sorvete desenvolvido com $55 \%$ de leite de coco e $7 \%$ de leite em pó desnatado, observou-se acidez de $0,27 \%$ de ácido láctico no produto formulado (ABOULFAZLI; BABA, 2015), e em iogurte natural a acidez quantificada foi entre $0,85 \%$ e $0,98 \%$ de ácido láctico (SARVARI; MORTAZAVIAN; FAZELI, 2014). A lactose é um componente essencial para a fermentação láctica e produção de ácido láctico em iogurtes, bebidas lácteas e produtos lácteos fermentados (YULIANA; RANGGA; RAKHMIATI, 2010) e, como o alimento de leite de coco não continha lactose ou açúcar adicionado, não houve substrato para produção da acidez.

A quantificação de bactérias lácticas no alimento formulado apresentou valores médios de 4,09, 3,40, $3,60,3,79$ e $3,80 \log$ UFC/g (Figura 1), consecutivamente, com diferença significativa $(p<0,05)$ apenas entre $o$ 5o e o 20 ㅇ dia avaliados. As baixas quantidades de carboidratos disponíveis e de proteínas no leite de coco podem explicar este decréscimo inicial da contagem de bactérias lácticas, posto que não houve adição de nenhuma outra fonte destes compostos e a quantidade presente não favoreceu sua multiplicação. Após o 20 을 dia, as variações nas contagens não foram significativas, demonstrando estabilização deste grupo microbiano no produto. Os valores permaneceram abaixo do limite mínimo estabelecido de $6 \log$ UFC/mL de bactérias lácticas para leites fermentados (BRASIL, 2007), mas o fato de as contagens manterem-se estáveis pode indicar que a inclusão inicial de uma quantidade maior de bactérias probióticas seja suficiente para atingir o padrão legal estipulado para o produto lácteo similarigura 1 - Contagem de bactérias lácticas no alimento à base de leite de coco durante o armazenamento refrigerado

Figura 1 - Contagem de bactérias lácticas no alimento à base de leite de coco durante o armazenamento refrigerado

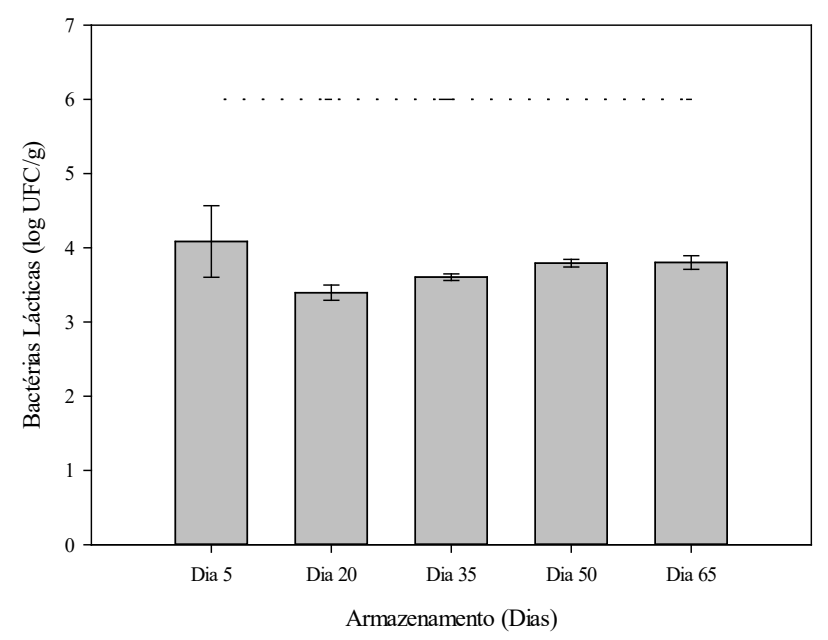

As barras verticais indicam a média \pm desvio padrão da média e a linha tracejada indica o valor mínimo para bactérias lácticas em leites fermentados (BRASIL, 2007).

Uma avaliação sobre a qualidade de diferentes marcas de leites fermentados comercializadas no mercado brasileiro constatou que $28 \%(n=7)$ não atingiu a 
contagem mínima exigida pela legislação (CASTILHO; CUNHA; ARAÚJO, 2013). Outro estudo com cinco marcas de iogurtes contendo polpa de frutas demonstrou contagens de bactérias lácticas acima de 9 log UFC/g no primeiro dia, diminuindo para $6 \mathrm{log}$ UFC/g ao final de 44 dias de armazenamento a 7 으, e decaindo abaixo do limite mínimo em temperaturas de 15 으, consideradas pelos autores como as que os produtos são mantidos durante a distribuição no varejo (ALMEIDA et al., 2015). Em outros estudos observou-se que o Lactobacillus rhamnosus foi o mais resistente à interrupção da estocagem a frio em iogurtes com adição de probióticos (FERDOUSI et al., 2013) e que houve perda de viabilidade do Bifidobacterium animalis subsp. lactis e Lactobacillus acidophilus em iogurtes sob armazenamento refrigerado (FERDOUSI et al., 2013; SARVARI; MORTAZAVIAN; FAZELI, 2014; YILMAZ-ERSAN; KURDAL, 2014). Estes resultados demonstraram que a contagem de bactérias lácticas totais é dependente das temperaturas de refrigeração, e que variações no armazenamento de produtos de base láctea podem levar à não conformidades com a legislação vigente.

$\mathrm{O}$ alimento formulado à base de leite de coco atingiu contagem de bactérias lácticas totais da ordem de 4 log UFC/g (Figura 1), entretanto a matéria-prima vegetal não possui componentes como hidrolisados proteicos, caseína e soro, classificados como facilitadores da multiplicação de bactérias lácticas (CASTILHO; CUNHA; ARAÚJO, 2013; FERDOUSI et al., 2013), nem aditivos como açúcar, considerados pela indústria como fundamentais para o crescimento de bactérias lácticas e probióticas, ou fruto-oligossacarídeos, que aumentaram significativamente a contagem das bactérias probióticas (OZCAN et al., 2016; WHITE; HEKMAT, 2018; SAVEDBOWORN et al., 2017). Os microrganismos utilizados no alimento à base de leite coco - Lactobacillus delbrueckii subsp. bulga- ricus, Streptococcus salivarius subsp. thermophilus, Lactobacillus acidophilus e Bifidobacterium - são usualmente utilizados em produtos de base láctea. Para estes permanecerem viáveis, é necessário $\mathrm{pH}$ próximo a 4,5, o que não foi alcançado no alimento à base de leite de coco (Tabela 1). Um estudo avaliou a viabilidade dos probióticos Bifidobacterium animalis subsp. lactis e Lactobacillus acidophilus em sorvetes de leite de coco e de leite bovino e observou-se que a primeira matriz foi pior para a manutenção destes microrganismos, provavelmente porque as proteínas do coco têm menor propriedade emulsificante que as proteínas lácteas bovinas, acarretando revestimento proteico menos estável em torno dos probióticos (ABOULFAZLI; BABA, 2015). O alimento à base do leite de coco formulado no presente estudo não teve disponibilidade de substrato e $\mathrm{pH}$ favorável para o crescimento das bactérias lácticas.

A Tabela 2 apresenta os resultados das contagens de coliformes totais e termotolerantes, psicrotróficos e bolores e leveduras. As contagens para os grupos coliformes totais e termotolerantes no alimento de leite de coco foram menores que 0,48 log NMP/g em todos os tempos de coleta, resultados condizentes com os limites estipulado pela legislação para leites fermentados (BRASIL, 2001; BRASIL, 2007). O grupo coliformes é indicador da qualidade higiênico-sanitária, e valores baixos demonstram que as condições de processamento e manipulação foram adequadas para este tipo de alimento (FORSYTHE, 2013).

A contagem de microrganismos psicrotróficos variou de 2,19 a 2,62 log UFC/g (Tabela 2), sem alterações significativas ao longo do período de armazenamento refrigerado. Em outro estudo com leites fermentados de duas marcas comerciais, a contagem para este grupo foi inferior a $1 \mathrm{log}$ UFC/g (NESPOLO et al., 2014). A proliferação excessiva de psicrotróficos pode

Tabela 2 - Contagens de coliformes totais e termotolerantes, psicrotróficos e bolores e leveduras no alimento à base de leite de coco durante o armazenamento refrigerado

\begin{tabular}{|c|c|c|c|c|}
\hline Período & $\begin{array}{l}\text { Coliformes totais } \\
\quad(\log N M P / g)\end{array}$ & $\begin{array}{l}\text { Coliformes termotolerantes } \\
(\log \mathrm{NMP} / \mathrm{g})\end{array}$ & $\begin{array}{l}\text { Psicrotróficos } \\
\text { (log UFC/g) }\end{array}$ & $\begin{array}{l}\text { Bolores e leveduras } \\
\quad \text { (log UFC/g) }\end{array}$ \\
\hline Dia 5 & Menor que $0,48^{a}$ & Menor que $0,48^{a}$ & $2,19 \pm 0,58^{a}$ & $3,38 \pm 0,06^{a}$ \\
\hline Dia 20 & Menor que $0,48^{a}$ & Menor que $0,48^{a}$ & $2,42 \pm 0,17^{a}$ & $3,38 \pm 0,07^{a}$ \\
\hline Dia 35 & Menor que $0,48^{a}$ & Menor que $0,48^{a}$ & $2,52 \pm 0,02^{a}$ & $4,08 \pm 0,05^{b}$ \\
\hline Dia 50 & Menor que $0,48^{a}$ & Menor que $0,48^{a}$ & $2,52 \pm 0,06^{a}$ & $9,48 \pm 0,01^{c}$ \\
\hline Dia 65 & Menor que $0,48^{a}$ & Menor que $0,48^{a}$ & $2,62 \pm 0,17^{a}$ & $9,48 \pm 0,01^{c}$ \\
\hline Padrão* & Máximo 1,0 & Máximo 0,48 & - & Máximo 1,7 \\
\hline
\end{tabular}

Valores apresentados como média \pm desvio padrão da média ( $n=3)$; a-c: Letras iguais na mesma coluna não diferem estatisticamente entre si $(p<0,05)$ pelo Teste de Tukey; *Padrão para leites fermentados (BRASIL, 2001, 2007). 
ocasionar danos na textura, sabor e consistência dos alimentos de origem láctea, posto que a contaminação pode ocorrer por falhas nos procedimentos higiênicos na manipulação das matérias-primas e de equipamentos e utensílios utilizados para este fim (FORSYTHE, 2013). As bactérias lácticas adicionadas crescem em temperaturas de refrigeração e podem ser quantificadas no grupo de psicrotróficos (FORSYTHE, 2013). As contagens verificadas no presente estudo, portanto, podem incluir parte das bactérias lácticas probióticas, levando-se em conta que a quantificação de bactérias lácticas foi realizada em condições de anaerobiose e a de psicrotróficos ocorreu com incubação em atmosfera normal, o que pode explicar as diferenças observadas nos resultados de cada grupo.

A contagem de bolores e leveduras no alimento à base de leite de coco demonstrou valores crescentes de 3,38 a 9,48 log UFC/g (Tabela 2). Apesar de não haver sinais visíveis de deterioração fúngica no produto, as amostras estariam reprovadas em todos os tempos de coleta. A avaliação em diferentes lotes de leites fermentados desnatados de cinco marcas, indicou ausência de bolores e leveduras em todas as amostras (CASTILHO; CUNHA; ARAÚJO, 2013), enquanto as contagens variaram de 2,7 a 4,7 log UFC/mL em estudo com duas apresentações comerciais (NESPOLO et al., 2014). A presença de bolores e leveduras no alimento é preocupante, pois este grupo é indicativo de má conservação e condições higiênicas insatisfatórias ou manutenção em temperaturas inadequadas (FORSYTHE, 2013).

Os resultados obtidos no presente estudo com o alimento à base de coco podem indicar que a matéria-prima de origem vegetal necessite de tratamento térmico adicional para evitar a contaminação fúngica.

Um estudo avaliou a vida útil e a taxa de deterioração diária para cinco amostras comerciais de iogurte, baseando-se na contagem de bactérias lácticas totais, e os resultados indicaram que a vida útil destes produtos foi de 39 a 40 dias, quando armazenados a 7으 (ALMEIDA et al., 2015). Considerando-se que esta foi a temperatura de conservação do alimento à base de leite de coco e que a multiplicação de bolores e leveduras se intensificou a partir dos 35 dias de armazenamento refrigerado, este prazo de vida útil poderia ser utilizado como base em novos testes.

\section{CONSIDERAÇÕES FINAIS}

Mediante a caracterização físico-química do alimento à base de leite de coco, foi possível constatar valores elevados de $\mathrm{pH}$ e de atividade de água e baixa acidez, o que indica um produto com risco de contaminação microbiológica. A verificação microbiológica evidenciou que o alimento de leite de coco estava em conformidade para coliformes totais e termotolerantes em todos os tempos de coleta, no entanto foi observada uma contaminação excessiva por bolores e leveduras durante o tempo de armazenamento de 65 dias. Aliada a isso, a contagem de bactérias lácticas não atingiu o valor de referência para leites fermentados, uma vez que a matéria-prima principal da formulação é de origem vegetal e não possui facilitadores de multiplicação destas bactérias. $O$ alimento à base de leite de coco aparece como uma alternativa de produto de origem vegetal contendo probióticos, entretanto é necessária a adição de substratos que facilitem a multiplicação dos microrganismos benéficos e cuidados adicionais no processamento para evitar a contaminação microbiológica.

\section{REFERÊNCIAS}

ABOULFAZLI, F.; BABA, A. S. Effect of Vegetable Milk on Survival of Probiotics in Fermented Ice Cream under Gastrointestinal Conditions. Food Science and Technology Research, Tsukuba, v. 21, n. 3, p. 1 -7, 2015.

ALMEIDA, D. M. et al. Determinação do tempo de vida de prateleira de iogurte com polpa de fruta por meio da população de bactérias láticas totais. Revista Brasileira de Tecnologia Agroindustrial, Curitiba, v. 9, n. 1, p. 1.671-1.681, 2015.

ANVISA. Agência Nacional de Vigilância Sanitária. Alimentos com alegações de propriedades funcionais e/ou de saúde. 2016. Disponível em: http://portalnvisaovr/alimentos/alegacoes. Acesso em: 22 mar. 2017.

BRASIL. Ministério da Agricultura, Pecuária e Abastecimento (Mapa). Instrução Normativa no 46, 23 de outubro de 2007. Regulamento técnico de identidade e qualidade de leites fermentados. Diário Oficial da União, Brasília, 24 set. 2007. Seção 1.

BRASIL. Ministério da Saúde. Agência Nacional de Vigilância Sanitária. Resolução-RDC no 12, de 2 de janeiro de 2001. Regulamento técnico sobre padrões microbiológicos para alimentos. Diário Oficial da União, Brasília, 2 jan. 2001. Seção 1.

CASTILHO, N. P. A.; CUNHA, A. F.; ARAÚJO, M. M. P. Qualidade de leites fermentados brasileiros e atividade antagonista in vitro de suas bactérias ácido láticas. Centro de Pesquisa e Processamento de Alimentos, Curitiba, v. 31, n. 2, p. 207214, 2013.

DECAGON DEVICES. Water Activity Meter: Operator's Manual. Disponível em: http://aqualabecagonomr/assets/ Uploads/13484-08-AquaLab-4df. Acesso em: 26 fev. 2019. 
DOWARAH, R. et al. Selection and characterization of probiotic lactic acid bacteria and its impact on growth, nutrient digestibility, health and antioxidant status in weaned piglets. PLoS One, San Francisco, v. 13, n. 3, p. 1-24, 2018.

FERDOUSI, R. et al. Evaluation of Probiotic Survivability in Yogurt Exposed To Cold Chain. Iranian Journal of Pharmaceutical Research, Tehran, v. 12, p. 139-144, 2013.

FOOD RESEARCH CENTER. Universidade de São Paulo (USP). Tabela Brasileira de Composição de Alimentos (TBCA). Versão 6.0. 2017. Disponível em: http://wwwcfspr/tbca/. Acesso em: 1o fev. 2019.

FOROUHI, N. G. et al. Dietary and nutritional approaches for prevention and management of type 2 diabetes. BMJ, London, n. 361, p. 1-9, 2018.

FORSYTHE, S. J. Microbiologia da segurança dos alimentos. 2. ed. Porto Alegre: Artmed, 2013. 607p.

HEINE, R. G. et al. Lactose intolerance and gastrointestinal cow's milk allergy in infants and children - common misconceptions revisited. World Allergy Organization Journal, Amsterdan, v. 10, n. 1, p. 41-48, 2017.

HILL, C. et al. Expert consensus document. The International Scientific Association for Probiotics and Prebiotics consensus statement on the scope and appropriate use of the term probiotic. Nature Reviews Gastroenterology \& Hepatology, New York, v. 1, n. 8, p. 506-514, 2014.

IAL. Instituto Adolfo Lutz. Métodos físico-químicos para análise de alimentos. São Paulo: Instituto Adolfo Lutz, 2008. 1.020 p. Cap. 4, p. 103-105.

LADOKUN, O.; ONI, S. Fermented Milk Products from Different Milk Types. Food and Nutrition Sciences, Wuhan, n. 5, p. 1.228-1.233, 2014.

MCFARLAND, L. V. From Yaks to Yogurt: The History, Development, and Current Use of Probiotics. Clinical Infectious Diseases, Oxford, v. 60, p. S85-S90, 2015.

MIJAN, M. A.; LIM, B. O. Diets, functional foods, and nutraceuticals as alternative therapies for inflammatory bowel disease: Present status and future trends. World Journal of Gastroenterology, Pleasanton, v. 24, n. 25, p. 2.673-2.685, 2018.

NESPOLO, C. R. et al. Análise de microrganismos presentes em amostras de leite fermentado durante a vida de prateleira do produto. CONGRESSO DE PESQUISA E EXTENSÃO DA FSG, 2., 2014, Caxias do Sul. Anais [...]. Caxias do Sul, 2014. p. 388- 399.
NEPA. Núcleo de Estudos e Pesquisas em Alimentação. Universidade Estadual de Campinas (Unicamp). Tabela Brasileira de Composição de Alimentos (Taco). 4. ed. 161 p. Disponível em: http://wwwepanicampr/taco/tabelahp?ativo=tabela. Acesso em: 1ㅇ fev. 2019.

OZCAN, O. et al. The Use of Prebiotics of Plant Origin in Functional Milk Products. Food Science and Technology, Campinas, v. 4, n. 2, p. 15-22, 2016.

PATIL, U.; BENJAKUL, S. Coconut Milk and Coconut Oil: Their Manufacture Associated with Protein Functionality. Journal of Food Science, Chicago, v. 83, n. 8, p. 2.019-2.027, 2018.

PATIL, U. et al. A comparative study of the physicochemical properties and emulsion stability of coconut milk at different maturity stages. Italian Journal of Food Science, Pinerolo, v. 29, n. 1, p. 145-57, 2017.

SARVARI, F.; MORTAZAVIAN, A. M.; FAZELI, M. R. Biochemical Characteristics and Viability of Probiotic and Yogurt Bacteria in Yogurt during the Fermentation and Refrigerated Storage. Applied Food Biotechnology, Tehran, v. 1, n. 1, p. 55-61, 2014.

SAVEDBOWORN, W. et al. Impact of inulin on viability and storage stability of probiotic Lactobacillus plantarum TISTR 2075 in fermented rice extract. Agriculture and Natural Resources, Bangkok, v. 51, p. 463-469, 2017.

SILVA, N. et al. Manual de métodos de análise microbiológica de alimentos e água. 5. ed. São Paulo: Blucher, 2017. 535pZILAGYI, A.; ISHAYEK, N. Lactose Intolerance, Dairy Avoidance, and Treatment Options. Nutrients, Basel, v. 10, n. 12, p. 1.994-2.023, 2018.

WHITE, J.; HEKMAT, S. Development of Probiotic Fruit Juices Using Lactobacillus rhamnosus GR-1 Fortified with Short Chain and Long Chain Inulin Fiber. Fermentation, Basel, v. 4, n. 27, p. 1-12, 2018.

YILMAZ-ERSAN, L.; KURDAL, E. The Production of Set-TypeBio-Yoghurt with Commercial Probiotic Culture. International Journal of Chemical Engineering and Applications, Singapura, v. 5, n. 5, p. 402-408, 2014.

YULIANA, N.; RANGGA, A.; RAKHMIATI, A. Manufacture of fermented coco milk-drink containing lactic acid bacteria cultures. African Journal of Food Science, Lagos, v. 4, n. 9, p. 558-562, 2010. 